\title{
Anomalous Coronary Artery From the Opposite Sinus (ACAOS): Technical Challenges During Percutaneous Coronary Intervention
}

\author{
Santosh Kumar Sinha ${ }^{\mathrm{a}, \mathrm{b}}$, Mahmodula Razi ${ }^{\mathrm{a}}$, Anupam Mahrotra ${ }^{\mathrm{a}}$, Puneet Aggarwal ${ }^{\mathrm{a}}$, \\ Anupam Singh ${ }^{\mathrm{a}}$, Lokendra Rekwal ${ }^{\mathrm{a}}$, Sunil Tripathi ${ }^{\mathrm{a}}$, \\ Nishant Kumar Abhishekha, Vinay Krishna ${ }^{a}$
}

\begin{abstract}
Anomalies of the coronary arteries are reported in 1-2\% of patients among diagnostic angiogram. Ectopic origin of right coronary artery (RCA) from opposite sinus is one of the most common and they are mainly benign, but at times may be malignant. We report a case of a 69-year-old male who underwent early invasive percutaneous coronary intervention for non-ST-segment elevation myocardial infarction (NSTEMI) where RCA arising from left sinus at the root of left main artery was culprit and various technical challenges were encountered while intervening in form of cannulation to tracking of hardwares. RCA was cannulated with floating wire technique using hockey stick guide catheter and revascularized by deployment of $3.5 \times 38 \mathrm{~mm}$ Promus Premier Everolimus eluting stent (Boston Scientific, USA). To the best of our knowledge, this is the first ever report of ectopic RCA being revascularized by using hockey stick catheter.
\end{abstract}

Keywords: Anomalous right coronary artery; Floating wire technique; Hockey stick guide; Early invasive intervention; Non-ST segment elevation myocardial infarction

\section{Introduction}

Malformation within coronary buds on the aortic sinuses or vascular plexuses to which they connect during fetal development leads to coronary artery anomalies whose incidence varies from $0.6 \%$ to $1.5 \%$, where patients may be asymptomatic or may present with stormy course [1-3]. Incidence of ectopic right coronary artery (RCA) from left aortic sinus is $0.92 \%$ and by nature, is benign and an incidental finding on coronary

Manuscript submitted November 9, 2017, accepted November 16, 2017

aDepartment of Cardiology, LPS Institute of Cardiology, G.S.V.M. Medical College, Kanpur, Uttar Pradesh, 208002, India

${ }^{b}$ Corresponding Author: Santosh Kumar Sinha, Department of Cardiology, LPS Institute of Cardiology, G.S.V.M. Medical College, Kanpur, Uttar Pradesh, 208002, India. Email: fionasan@rediffmail.com

doi: https://doi.org/10.14740/cr630w angiogram [3]. Sometimes, it may be complicated with atherosclerosis and present with various spectra of coronary artery disease. Intervening such artery is a different scenario as different guide catheters with variable support and tracking of hardwares become paramount issue.

\section{Case Report}

A 69-year-old male smoker with a past history of diabetes mellitus and dyslipidemia presented with retrosternal chest pain and profuse sweating of $12 \mathrm{~h}$ duration. His physical examination and biochemistry were all unremarkable. Echocardiography revealed mild hypokinesia in RCA territory with ejection fraction of $49 \%$. Electrocardiogram revealed ST depression and $\mathrm{T}$ inversion in II, III, aVF, and $\mathrm{V}_{1}-\mathrm{V}_{3}$. In the laboratory analysis, creatine kinase MB (CKMB) was 97 U/L (upper limit $25 \mathrm{U} / \mathrm{L}$ ), and troponin I was $5.89 \mathrm{ng} / \mathrm{mL}$ (upper limit 0.01 $\mathrm{ng} / \mathrm{mL}$ ). In lieu of ongoing angina and high troponin level, he was taken for early invasive coronary intervention through femoral route after proper consent. He was preloaded with prasugrel $60 \mathrm{mg}$, aspirin $325 \mathrm{mg}$ and atorvastatin $80 \mathrm{mg}$. The 6-F JR3.5 and JL3.5 Proflo ${ }^{\mathrm{TM}}$ diagnostic catheters (Medtronic, USA) were used for catheterization after administering 2,500 $\mathrm{U}$ of heparin. Basal angiogram revealed normal left system (left anterior descending artery and left circumflex artery) and ectopic RCA (arising near the root of left main trunk) from left aortic sinus with downward course showing discrete eccentric critical lesion in mid segment with 95\% stenosis (Fig. $1 \mathrm{a}, \mathrm{b}$ ). Percutaneous intervention of culprit artery was planned with further administration of 7,000 $\mathrm{U}$ of heparin. We tried to cannulate RCA with Judkins left and right (JL, JR), multipurpose (MPA 1, 2), Amplatz left (AL), Amplatz right (AR), and Tiger diagnostic catheter (Terumo, Japan), but failed to cannulate selectively because of its anomalous origin and course. Finally, hockey stick catheter (Boston Scientific, USA) was kept afloat near its ostia by giving a counter clockwise turn to keep it little away from left main trunk (Figs. 2, 3a). We provided a big curve to $0.014 "$ runthrough wire (Terumo, Japan) and by floating in the left sinus, RCA was cannulated and wire was parked distally (Fig. 3a). Lesion was predilated with 2.5 $\times 10 \mathrm{~mm}$ Minitrak balloon (Abott, USA) and stented with 3.5 $\times 38$ Promus Premier stent (Everolimus eluting stent, Boston 


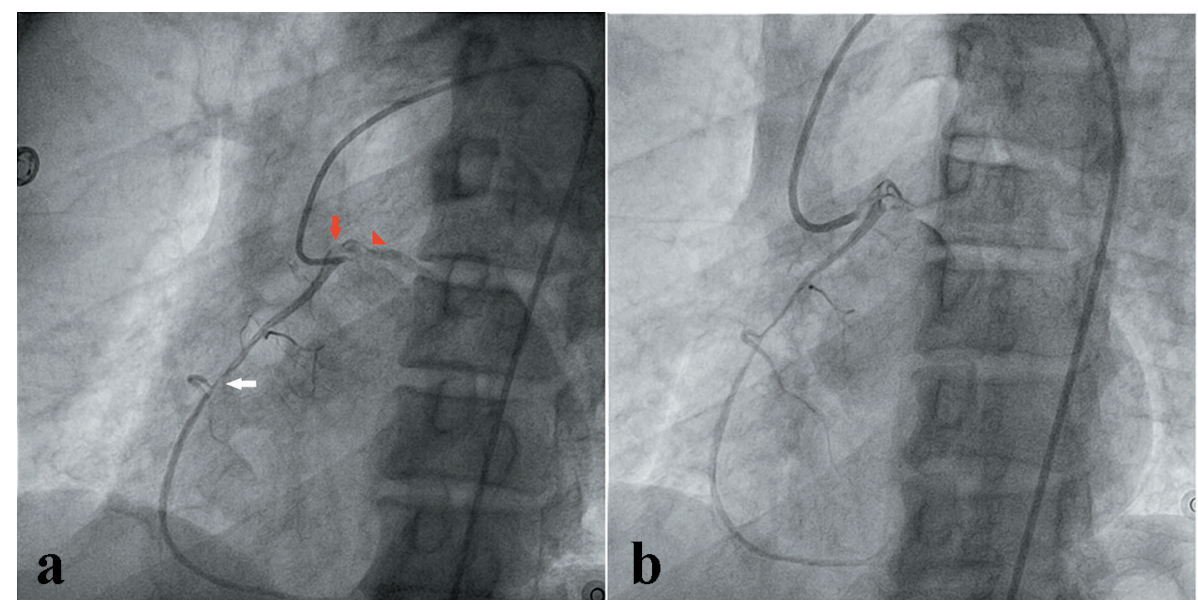

Figure 1. Right coronary artery arising from left aortic sinus near the base of left main trunk showing discrete eccentric critical lesion in mid segment (a). Failure to cannulate right coronary artery with various catheter (b).

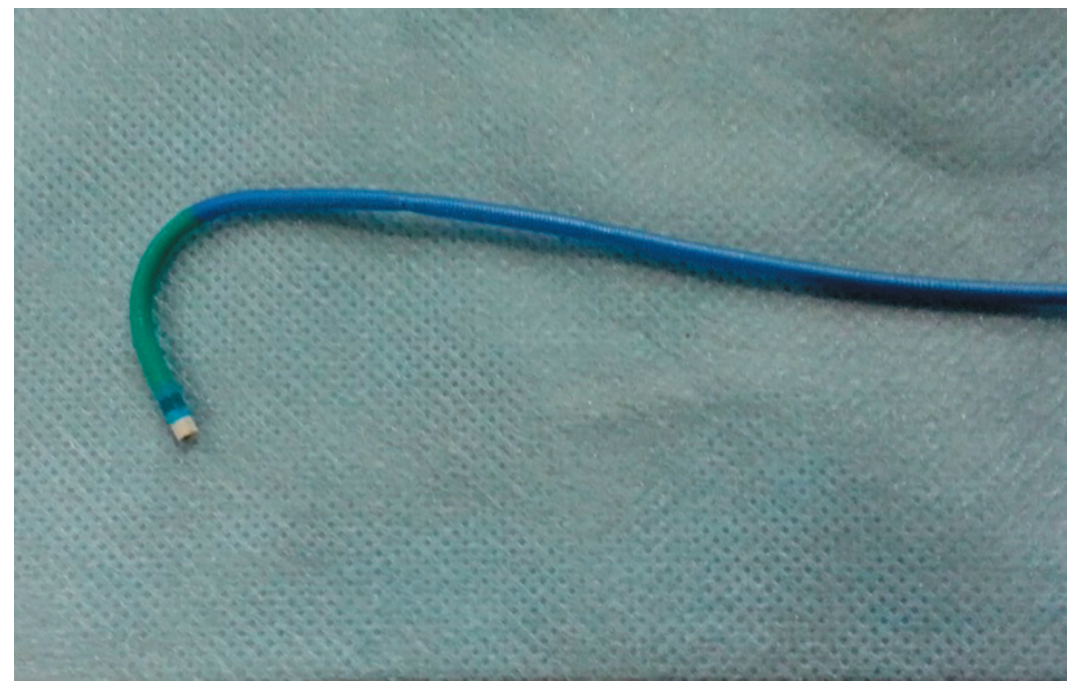

Figure 2. Typical design of hockey stick guiding catheter.

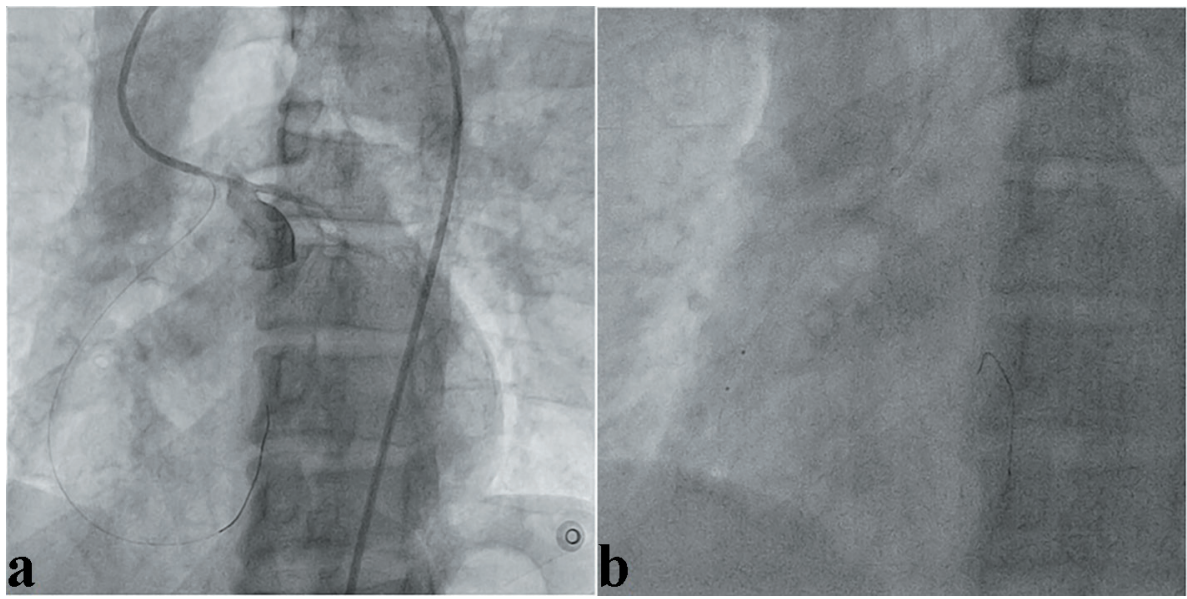

Figure 3. Hockey stick guiding catheter was kept afloat near its ostia (a). Right coronary artery being cannulated with floating wire technique and lesion being predilated (b). 


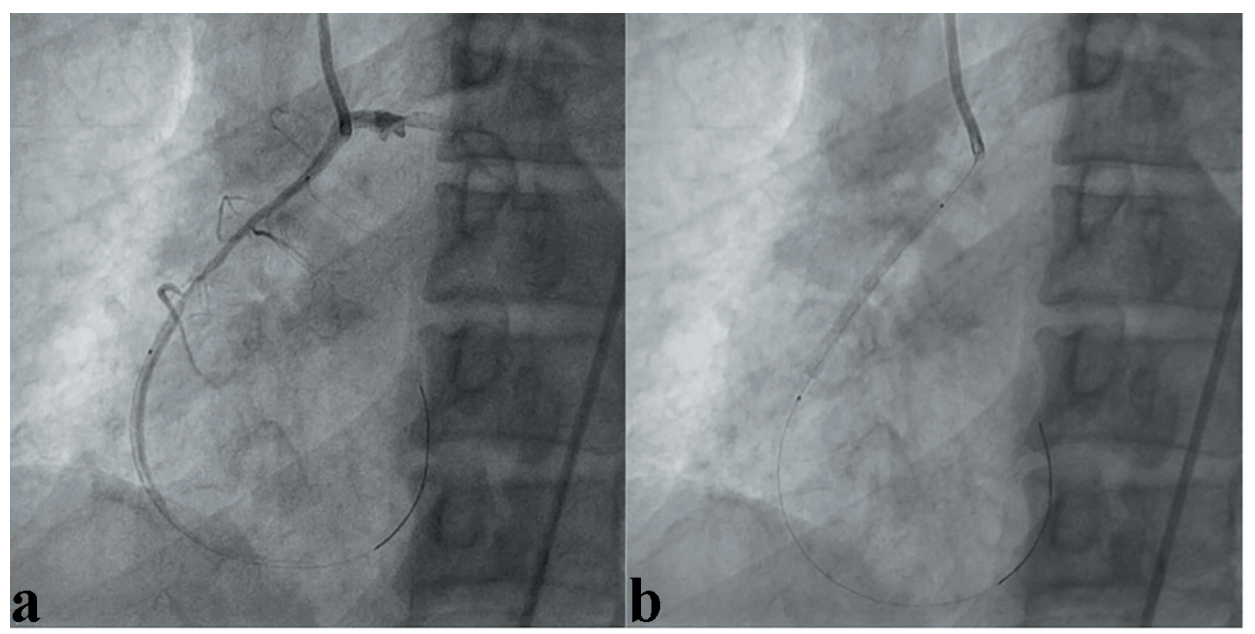

Figure 4. Lesion being stented with $3.5 \times 33 \mathrm{~mm}$ Xience Prime stent at $12 \mathrm{~atm}$ pressure $(\mathrm{a}, \mathrm{b})$.

Scientific, USA) deploying at $10 \mathrm{~atm}$ pressure (Figs. 3b, 4a, b) and further postdilated with $3.5 \times 10 \mathrm{~mm}$ non-compliant Minitrak balloon at 20 atm pressure achieving TIMI III flow (Fig. 5). His symptom and ECG stabilized. Multidetector coronary computer tomography angiogram (MDCT) showed the aberrant RCA arising from left coronary sinus near left main ostium (Fig. 6a, b). He was discharged on the third day with aspirin $150 \mathrm{mg} /$ day, prasugrel $10 \mathrm{mg} /$ day, atorvastatin $80 \mathrm{mg} /$ day, metoprolol $100 \mathrm{mg} /$ day and ramipril $2.5 \mathrm{mg} /$ day. Patient is doing excellent since then with regular follow-up at our in- stitute.

\section{Discussion}

The most common locations of ectopic RCA are the left sinus which may be anterior, superior $[4,5]$ either from the left sinus itself or directly from the left main coronary artery or its vicinity [6]. Mostly they are an incidental finding diagnosed on routine angiogram and rarely present with coronary artery

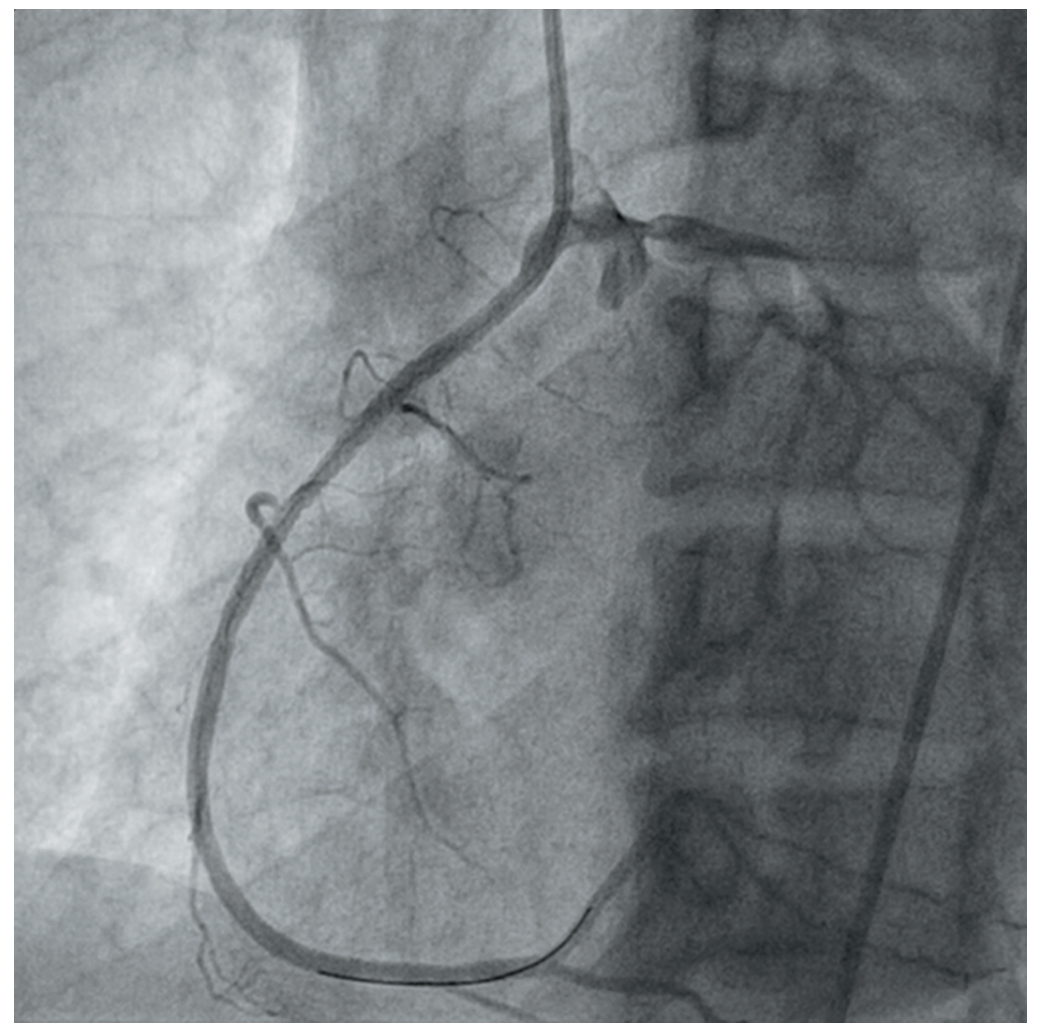

Figure 5. Right coronary artery showing TIMI III flow with well deployed stent after high pressure post dilatation. 


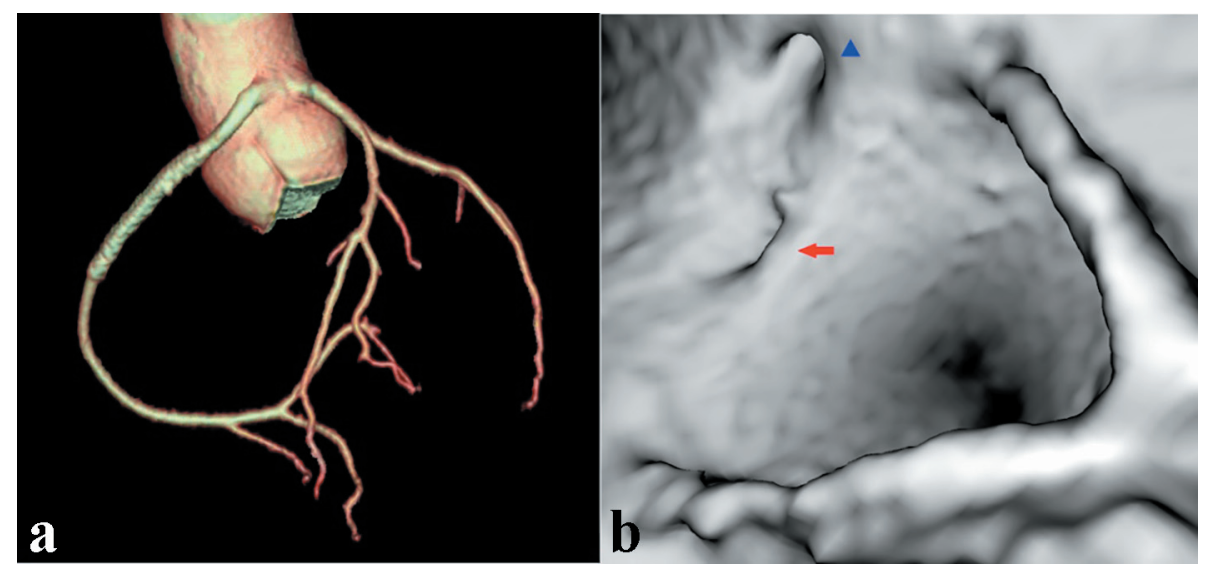

Figure 6. MDCT showing ectopically arising RCA with from left sinus (a). Volume rendered reconstruction from inside aorta showing RCA ostium (blue arrow head) lying in close vicinity of base of left main trunk (red arrow) (b).

disease. During routine angiography, they can be cannulated selectively by conventional right diagnostic catheters (JR 3.54, AR 1-2), unconventional Williams no-torque curves, Tiger catheter or non-selective sinus root injection as support is not a consideration.

Data regarding successful percutaneous revascularization of ectopic RCA from left sinus are limited mostly in the form of small case series [7-9]. Selection of a guide catheter will depend upon dimensions of the aortic root, desired level of backup support, takeoff angle, location of the lesion, and the hardwares to be used during revascularization. RCA intervention using Judkins guiding catheters is associated with a lack of strong back-up support and an inability to deep-seat, whereas Amplatz guiding catheters although have excellent support but at the cost of risk of too deep intubation causing hemodynamic compromise and rarely ostial dissection [10].

\section{Design of hockey stick catheter}

Its unique design overcomes above limitations. Contrary to its name, it is L-shaped because of its primary and secondary curves and can be better considered as modified Amplatz catheter without its primary curve [10]. It provides an excellent back-up support and permits balloon tracking when enhanced back-up support is required. Technically, it is simple to use as it can easily engage and disengage without any clockwise or counter-clockwise rotations. Once engaged, it is gently withdrawn until its curve is straighten and comfortably seated in the ostia.

Sometimes, alignment is non-co-axial where guide may back out which can be circumvented by using floating wire technique. Since initial entry to anomalous RCA needs the floating of wire, we recommend the wider curve to be administered to the wire. Once wire is distally parked, guide can be deeply intubated with distally inflated appropriate sized balloon acting as an anchor but caution must be exercised if plaque is located in osteo-proximal segment. In one of the largest series of anomalous RCA by Sarkar et al [11], they have used JL, JR, Q-curve, and Voda catheter for RCA cannulation.
To the best our knowledge, we are reporting for the first time the use of hockey stick catheter and floating wire technique for revascularization of anomalous RCA.

\section{Acknowledgments}

We acknowledge Vinay Singh, radiation safety officer for technical support in CT image reconstruction.

\section{Conflict of Interest}

None.

\section{References}

1. Bogers AJ, Gittenberger-de Groot AC, Poelmann RE, Peault BM, Huysmans HA. Development of the origin of the coronary arteries, a matter of ingrowth or outgrowth? Anat Embryol (Berl). 1989;180(5):437-441.

2. Yamanaka O, Hobbs RE. Coronary artery anomalies in 126,595 patients undergoing coronary arteriography. Cathet Cardiovasc Diagn. 1990;21(1):28-40.

3. Angelini P, Villason S, Chan A V. Normal and anomalous coronary arteries in humans. In: Angelini P, editor. Coronary Artery Anomalies: A Comprehensive Approach. Philadelphia: Lippincott Williams \& Wilkins; 1999. p 42.

4. Grollman JH, Jr., Mao SS, Weinstein SR. Arteriographic demonstration of both kinking at the origin and compression between the great vessels of an anomalous right coronary artery arising in common with a left coronary artery from above the left sinus of Valsalva. Cathet Cardiovasc Diagn. 1992;25(1):46-51.

5. Yans J, Kumar SP, Kwatra M. Anomalous origin of the right coronary artery above the left sinus of Valsalva. Cathet Cardiovasc Diagn. 1978;4(4):407-412.

6. Husaini SN, Beaver WL, Wilson IJ, Lach RD. Anomalous right coronary artery arising from left mainstem. 
Cathet Cardiovasc Diagn. 1983;9(4):407-409.

7. Topaz O, DiSciascio G, Goudreau E, Cowley MJ, Nath A, Kohli RS, Vetrovec GW. Coronary angioplasty of anomalous coronary arteries: notes on technical aspects. Cathet Cardiovasc Diagn. 1990;21(2):106-111.

8. Musial B, Schob A, de Marchena E, Kessler KM. Percutaneous transluminal coronary angioplasty of anomalous right coronary artery. Cathet Cardiovasc Diagn. 1991;22(1):39-41.
9. Chakraborty B, Chan CN, Tan A. Percutaneous transluminal coronary angioplasty of an anomalous right coronary artery arising from a separate ostium in the left sinus of Valsalva. A case report. Angiology. 1995;46(7):629-632.

10. Mehta S, Margolis JR. Hockey stick guiding catheter. J Interv Cardiol. 1992;5(4):331-336.

11. Sarkar K, Sharma SK, Kini AS. Catheter selection for coronary angiography and intervention in anomalous right coronary arteries. J Interv Cardiol. 2009;22(3):234-239. 